\title{
Design Swelling Micas: Insights on Heavy Metals Cation
}

\section{Exchange Reaction.}

Francisco J. Osuna ${ }^{1}$, Esperanza Pavón ${ }^{1}$, María D. Alba ${ }^{1, *}$

${ }^{1}$ Instituto Ciencia de los Materiales de Sevilla (CSIC-US). Avda. Américo Vespucio, 49. 41092-Sevilla, Spain

\begin{abstract}
Heavy metal pollution has become one of the most serious environmental problems, demanding specialized remediation mechanisms. Among the studied treatments, ionexchange processes have been widely used due to their high remediation capacity, efficiency and fast kinetic. Here, the potential use of a new family of design micas as cation exchanger has been analysed. Micas with a layer charge in the range of brittle micas have been synthesized and their heavy metals cation exchange capacity analysed as a function of the nature of the heavy metal cations $\left(\mathrm{Pb}^{2+}, \mathrm{Cd}^{2+}\right.$ or $\left.\mathrm{Hg}^{2+}\right)$, the nature of the counterions $\left(\mathrm{Cl}^{-}\right.$or $\left.\mathrm{NO}_{3}{ }^{-}\right)$, concentration of the solutions and the micas layer charge. A cation exchange ratio between $35 \%$ and $154 \%$ of their cation exchange capacity $(C E C)$ was achieved, being more efficient when mica layer charge diminished. In general, the maximum adsorption capacity followed the trend: $\mathrm{Hg}^{2+}>\mathrm{Pb}^{2+}>\mathrm{Cd}^{2+}$. The efficiency of the cation exchange and adsorption mechanism of the synthetic micas depended on the experimental conditions and they were more efficient than raw and modified natural clay minerals.
\end{abstract}

Keywords. heavy metals; hazardous materials; design clay; cation exchange capacity.

\footnotetext{
*Corresponding author: alba@icmse.csic.es
} 


\section{Introduction}

Heavy metal pollution has become one of the most serious environmental problems. Zinc, copper, nickel, mercury, cadmium, lead and chromium are the most hazardous heavy metals and, consequently, they are of particular concern in the treatment of industrial wastewaters, due to their recalcitrance and persistence in the environment. In recent years, various methods for heavy metal removal from wastewater have been extensively studied (Fu and Wang, 2011). Among them, ion-exchange processes have been widely used due to their high treatment capacity, high removal efficiency and fast kinetic (Kang et al., 2004).

Among the most used materials for ionic exchange, clay minerals and their derivatives are drawing wide concerns nowadays, differing from other materials such as activated carbon, zeolite, and resin in terms of the microstructure, adsorptive characteristics, and environmental applications (Churchman et al., 2006; Yuan, 2004; Yuan et al., 2013; Zhu et al., 2015). However, their use is still limited compared with synthetic resins and more research is needed for their application at an industrial scale and the use of alternative low-cost adsorbent materials have been emphasized.

The adsorption capacity of the natural clay minerals is quite limited (Syrmanova et al., 2016), thus, many studies have been devoted to enhance their metal uptake (Jimenez-Castaneda and Medina, 2017; O'Connell et al., 2008; Srinivasan, 2011). In his sense, Alba et al. (Alba et al., 2006) have synthetized a new family of the swelling high charged fluorophlogopite, with layer charge in the range of the brittle micas (Pavon et al., 2014) but unlike the natural micas, they exhibit swelling properties and cation exchange capacity (Pavon et al., 2013). Those synthetic micas, Na-Mn ( $n$ is the layer charge ranging between 2 and 4), have exhibited excellent capacity for radioactive cations and organic 
pollutants removal from wastewater (Alba et al., 2006; Garcia-Jimenez et al., 2016; Pazos et al., 2017) and are promising materials for heavy metal ion-exchange processes. Moreover, the use of synthetic samples is a potentially useful alternative for a proper understanding of the physical chemistry of the ion exchange reaction.

The present work provides basic and extensive information on cation exchange for divalent heavy metals cations as a function of structural parameters of the micas (layer charge) and experimental conditions such as nature of the heavy metals $\left(\mathrm{Pb}^{2+}, \mathrm{Cd}^{2+}\right.$ or $\mathrm{Hg}^{2+}$, which even in very low levels cause neurological, reproductive, cardiovascular, and developmental damage (Al-Saleh et al., 2008; Kim et al., 2012)), the counterions nature $\left(\mathrm{Cl}^{-}\right.$or $\left.\mathrm{NO}_{3}{ }^{-}\right)$or initial solution concentration. All the experimental variables have been summarized in Table 1.

\section{Experimental}

\subsection{Materials}

$\mathrm{Na}-\mathrm{M} n$ ( $n$ is the layer charge equals to 2 or 4 ) were synthetized by mixing $\mathrm{SiO}_{2}, \mathrm{Al}_{2} \mathrm{O}_{3}$, $\mathrm{MgF}_{2}$, and $\mathrm{NaCl}$ in the molar ratio 8-n:n:6:2n. The starting materials were $\mathrm{SiO}_{2}$ from Sigma (CAS no. 112945-52-5, 99.8\% purity), $\mathrm{Al}(\mathrm{OH})_{3}$ from Sigma Aldrich (CAS no. 21645-51-2, 99\% purity), $\mathrm{MgF}_{2}$ from Aldrich (CAS no. 20831-0, 98\% purity), and $\mathrm{NaCl}$ from Panreac (CAS no. 131659, 99.5\% purity). All reagents were mixed and ground in an agate mortar and, then, were heated up to $900^{\circ} \mathrm{C}$ for $15 \mathrm{~h}$ in a Pt crucible. Finally, the solids were washed with deionized water and dried at room temperature (Alba et al., 2006).

\subsection{Cation Exchange reaction}


The as-synthetized samples were equilibrated with solutions of $\mathrm{Pb}^{2+}, \mathrm{Cd}^{2+}$ and $\mathrm{Hg}^{2+}$, following the methodology described by Pavon el at. (Pavon et al., 2013). The most important characteristics of these ions in solutions are displayed in Table 2 (GonzalezDavila et al., 2007; Matusik and Wscislo, 2014; Pearson, 1988; Persson, 2010). Different parameters were tested in the equilibrium reaction in order to analyse the influence of each one (Table 1): initial solution concentration (Samples A vs Sample B), the nature of the counterion $\left(\mathrm{Cl}^{-}\right.$or $\mathrm{NO}_{3}{ }^{-}$, Samples $\mathrm{B}$ vs $\mathrm{C}$ ), stirring (Samples $\mathrm{C}$ vs D) and mica layer charge (Samples D). $500 \mathrm{mg}$ of solid were used and the reaction took place at $25^{\circ} \mathrm{C}$ during $24 \mathrm{~h}$, previous studies demonstrated that the equilibrium should be reached at this time (Kodama et al., 2000; Kodama et al., 2004). To avoid the hydrolysis of cations in the solution and the precipitation of metal hydroxides and oxides, the $p H$ of the solutions were previously set below 6 for $\mathrm{Pb}^{2+}$ and $\mathrm{Cd}^{2+}$ and below 2.5 for $\mathrm{Hg}^{2+}$ (Table $\mathrm{S} 1$ and Fig. S1) (Uddin, 2017). After equilibration, the solutions were centrifuged at $10000 \mathrm{rpm}$ for $20 \mathrm{~min}$. The whole equilibrium reaction with fresh solution and phase separation were repeated three more times. In all the cases, the solids were later washed with milli-Q water for four times.

The $p H$ and potential $\left(E_{H}\right)$ values of the supernatants were measured (Table S1 and Fig. S1) and, then, they were kept under acid and freezing conditions. The solids were dried at room temperature and grinded afterwards.

\subsection{Characterization}

ICP-AES (Inductively Coupled Plasma-Atomic Emission Spectrometry) was used to analyse the metal content on the initial solutions and the supernatants obtained after the equilibrium reactions. Measurements were carried out at microanalysis laboratory 
(CITIUS, University of Seville, Spain) using a HORIBA JOBIN YVON-ULTIMA 2 equipment.

Powder X-ray diffraction (XRD) was carried out to check the phase purity, to determine the basal spacing of the micas, and to monitor crystallinity. XRD patterns were obtained at the X-ray laboratory (CITIUS, University of Seville, Spain) on a Bruker D8 Advance instrument equipped with a $\mathrm{Cu} \mathrm{K}_{\alpha}$ radiation source operating at $40 \mathrm{kV}$ and 40 $\mathrm{mA}$. Diffractograms were obtained in the $2 \theta$ range of $3-70^{\circ}$ with a step size of $0.015^{\circ}$ and a step time of $0.1 \mathrm{~s}$.

Scanning electron microscopy (SEM/EDX) was used to determine particle size, shape and elemental composition of particles. The images were recorded at $20 \mathrm{kV}$ in the Microscopy Service of ICMS (CSIC-US) using a JEOL Model JSM 5400. An EDX system (Oxford Link ISIS) was fitted to the SEM equipment to perform chemical analyses of the sample using a $\mathrm{Si} / \mathrm{Li}$ detector with Be window.

Solid state nuclear magnetic resonance (MAS-NMR) was used to analyse the local order of the framework heteroatoms $\left({ }^{29} \mathrm{Si}\right.$ and ${ }^{27} \mathrm{Al}$ MAS NMR) and the evolution of the sodium in the interlayer space $\left({ }^{23} \mathrm{Na}\right.$ MAS NMR). Single-pulse (SP) MAS-NMR experiments were recorded on a Bruker AVANCE WB400 spectrometer equipped with a multinuclear probe, at the Nuclear Magnetic Resonance Service of University of Córdoba (Córdoba, Spain). Powdered samples were packed in $3.2 \mathrm{~mm}$ zirconia rotors and spun at $10 \mathrm{kHz} .{ }^{29} \mathrm{Si}$ MAS-NMR spectra were acquired at a frequency of $79.49 \mathrm{MHz}$, pulse width of $2.7 \mu \mathrm{s}(\pi / 6)$ each $3 \mathrm{~s} .{ }^{27} \mathrm{Al}$ MAS-NMR spectra were recorded at $104.26 \mathrm{MHz}$ with a pulse of $0.38 \mu \mathrm{s}(\pi / 20)$ and a delay time of $0.5 \mathrm{~s} .{ }^{23} \mathrm{Na}$ MAS NMR spectrum was recorded at $105.84 \mathrm{MHz}$ with a pulse width of $0.75 \mu \mathrm{s}(\pi / 2$ pulse length $=4.5 \mu \mathrm{s})$ and a delay time of $0.1 \mathrm{~s}$. The chemical shift values were reported in ppm from tetramethylsilane for ${ }^{29} \mathrm{Si}$ and from a $0.1 \mathrm{M} \mathrm{AlCl}_{3}$ and $\mathrm{NaCl}$ solution for ${ }^{27} \mathrm{Al}$ and ${ }^{23} \mathrm{Na}$, respectively. 


\section{Results and discussion}

The amount of desorbed sodium $\left(C_{d s}\right)$ and adsorbed heavy metals $\left(C_{s}\right)$ in Na-M4 samples were below its cation exchange capacity (Fig. 1). Two reasons can explain this behaviour: i) an equilibrium state between the cations in the mica interlayer space and those in solution: Na-M4 (s) $+\mathrm{X}^{2+}(\mathrm{aq})=\mathrm{Na} / \mathrm{X}-\mathrm{M} 4(\mathrm{~s})+\mathrm{Na}^{+} / \mathrm{X}^{2+}(\mathrm{aq})$, ii) a partial compensation of the layer charge by hydronium ions from the hydrolysis of the heavy metal cations in aqueous solution, and/or, iii) cations leached from the mica framework due to the acid medium.

In Na-M4, $\mathrm{Na}^{+}$was not completely desorbed and $\mathrm{X}^{2+}$ was adsorbed below the $C E C$ (Fig. 1), which indicates that beside cationic exchange reaction other mechanisms are involved in the adsorption. The only exceptions are samples Hg-M4-A and Hg-M4-D where it is below the $C E C$ probably due to a partial compensation of the layer charge by $\mathrm{H}_{3} \mathrm{O}^{+}$ions (Park et al., 2012) or leached framework cations to the interlayer space (Alba et al., 2001a, b).

For $\mathrm{Na}-\mathrm{M} 2, \mathrm{~Pb}^{2+}$ and $\mathrm{Cd}^{2+}$ are adsorbed above its $C E C$ although $\mathrm{Na}^{+}$is not completely desorbed whereas $\mathrm{Hg}^{2+}$ absorption is $76 \%$ of its $C E C$ and $\mathrm{Na}^{+}$is completely desorbed (Fig. 1). In the former, both cation exchange and precipitation are the mechanisms for the metal absorption. $\mathrm{Hg}^{2+}$ cation is more easily hydrolysable in aqueous solution than $\mathrm{Pb}^{2+}$ and $\mathrm{Cd}^{2+}\left(p K_{H}=3.4\right.$ (Gonzalez-Davila et al., 2007) vs the $p K_{H}=7.7$. or 10.1 for $\mathrm{Pb}^{2+}$ and $\mathrm{Cd}^{2+}$ (Matusik and Wscislo, 2014), Table 2, then, in the $\mathrm{Hg}^{2+}$ exchange reaction, a partial compensation of the layer charge may occur due to $\mathrm{H}_{3} \mathrm{O}^{+}$ions (Park et al., 2012).

The XRD peak for 001 reflection remains strong for the divalent metal exchanged micas (Fig. 2) and the basal spacing ranges from 1.21 to $1.39 \mathrm{~nm}$ indicating that, after the 
exchange, the interlayer structure of the hydrated micas is retained as a single water sheet or double sheet of interlayer cation, respectively (Kodama and Komarneni, 1999).

Intercalated divalent cations influence the electrostatic attraction, which can be explained by cation hardness $(\eta)$. As previously reported for rare-earth cations (Takahashi et al., 2004), the interaction between interlayer cations and montmorillonite surface is favoured for hard cations. When the $\eta$ for the interlayer cations is high as $\mathrm{Cd}^{2+}, 10.29$, (Pearson, 1988) a unique 001 reflection at ca. $1.21 \mathrm{~nm}$, corresponding to a similar hydration state to $\mathrm{Na}^{+}$in $\mathrm{Na}-\mathrm{M} 4$, is observed. In contrast, when the $\eta$ ratio of the interlayer cations is low, as $\mathrm{Pb}^{2+}$ and $\mathrm{Hg}^{2+}, 8.46$ and 7.7 respectively, (Pearson, 1988) a more complex behaviour, with additional 001 reflections at high basal space, is observed. Higher basal space is observed for Hg-M4-A and $\mathrm{Hg}-\mathrm{M} 4-\mathrm{B}$ than for $\mathrm{Pb}-\mathrm{M} 4-\mathrm{A}$ and $\mathrm{Pb}-$ M4-B, in good agreement with their respectively hardness (Fig. 2).

Besides the mica structure and depending on the experiment, new crystalline phases are detected by XRD (Fig. 2), except for the $\mathrm{Cd}^{2+}$ samples that the mica phase remain unaltered. In $\mathrm{Pb}-\mathrm{M} 4-\mathrm{A}$ and $\mathrm{Pb}-\mathrm{M} 4-\mathrm{B}$, where the $\mathrm{pH}$ of initial solution was quite low, crystalline spinel is formed together with $\mathrm{PbCl}_{2}$ whereas in $\mathrm{Pb}-\mathrm{M} 4-\mathrm{C}$ and $\mathrm{D}$, lead oxide and fluorine are observed. In Hg-M4-C and Hg-M4-D, two crystalline phases containing $\mathrm{Mg}$ and/or $\mathrm{Si}$ are detected. $\mathrm{HgO}$ and $\mathrm{Hg}\left(\mathrm{NO}_{3}\right)_{3}$ crystalline phases are also observed in Hg-M4-C.

Scanning electron micrographs of all samples indicate that the morphology is not affected by the cation exchange reaction (figures non shown). However, the elemental composition of the layer changes with the experimental conditions (Fig. S2). After the exchange reactions, the intensity of $\mathrm{Na}_{\alpha}$ line diminishes and new lines representative of the heavy metal increases as expected from the elemental analysis results. On the other 
hand, the intensity of the framework $\mathrm{Si}, \mathrm{Al}$ and $\mathrm{Mg} \mathrm{K} \alpha$ lines changes depending on the experimental conditions.

It is remarkable, the absence of the $\mathrm{Hg} \mathrm{M}$ line in the EDX spectra of Hg-M4-A and Hg-M4-B (Fig. S2) although $\mathrm{Na}^{+}$was desorbed and $\mathrm{Hg}^{2+}$ was adsorbed (Fig. 1). This fact remarks that $\mathrm{Na}^{+}$could be exchanged by $\mathrm{H}_{3} \mathrm{O}^{+}$due to $\mathrm{Hg}^{2+} / \mathrm{Hg}_{2}{ }^{2+}$ hydrolysis or to framework cations leached in the acidic reaction medium (Table S1).

${ }^{23} \mathrm{Na}$ MAS NMR spectra of Na-Mn ( $n=2$ and 4) (Fig. 3) are characterized by a broad signal between 10 and $-30 \mathrm{ppm}$ due to exchangeable hydrated cation and, in the case of $\mathrm{Na}-\mathrm{M} 2$, an additional peak at ca. $37 \mathrm{ppm}$ due to non-exchangeable $\mathrm{Na}^{+}$is also observed (Naranjo et al., 2015). After the metal exchange reaction, the intensity of the exchangeable $\mathrm{Na}^{+}$signal decreases in good agreement with the quantity of remainder sodium after the exchange reaction (Fig. 1) and the intensity of the non-exchangeable ${ }^{23} \mathrm{Na}$ NMR signal of the $\mathrm{X}-\mathrm{M} 2-\mathrm{D}\left(\mathrm{X}=\mathrm{Pb}^{2+}\right.$ and $\left.\mathrm{Cd}^{2+}\right)$ spectra remains constant. Especial attention demands the ${ }^{23} \mathrm{Na}$ MAS NMR spectrum of Hg-M2-D, the signal of the exchangeable hydrated cation (between 10 to $-30 \mathrm{ppm}$ ) disappears and the intensity of the signal at ca. 37 ppm decreases. The $\mathrm{Na}^{+}$desorbed by Hg-M2-D is slightly higher than their $C E C$ and it could account not only the exchangeable interlayer $\mathrm{Na}^{+}$but also part of non-exchangeable $\mathrm{Na}^{+}$that was leached in an acidic medium (Table $\mathrm{S} 1$ ) as pointed by ${ }^{23} \mathrm{Na}$ MAS NMR.

${ }^{27}$ Al MAS NMR spectra (Fig. S3) show an asymmetric band at ca. $67 \mathrm{ppm}$ corresponding to $\mathrm{Al}^{3+}$ in tetrahedral coordination (Sanz and Serratosa, 1984). The ${ }^{27} \mathrm{Al}$ MAS NMR spectrum for Na-M2 (Fig. S3) shows only this Al resonance at $67.3 \mathrm{ppm}$, indicating the presence of only tetrahedral $\mathrm{Al}^{3+}$, while Na-M4 (Fig. S3) has small amounts of octahedral coordinated $\mathrm{Al}^{3+}$ in $\mathrm{Mg}^{2+}$ trioctahedral sheets resonating at ca. $0 \mathrm{ppm}$. 
However, most of the $\mathrm{Al}^{3+}$ atoms are predominantly present in tetrahedral sheet as evidenced by the very strong tetrahedral $\mathrm{Al}^{3+}$ resonance at $68.5 \mathrm{ppm}$.

After cation-exchange reaction, a broadening of the ${ }^{27} \mathrm{Al}$ signals is observed, due to the distortion exerted on the tetrahedral $\mathrm{Al}^{3+}$ as consequence of the location of the interlayer cation in the pseudohexagonal cavity (Alvero et al., 1994). The exchange with $\mathrm{Hg}^{2+}$ also provokes an increasing in the octahedral ${ }^{27} \mathrm{Al}$ signal in $\mathrm{Hg}-\mathrm{M} 4$, due to the leached $\mathrm{Al}^{3+}$ as consequence of the low $p H$ value of the initial solution (Table S1). Part of this $\mathrm{Al}^{3+}$ could be responsible of satisfying the total $C E C$ capacity, especially in $\mathrm{Hg}$ M4-A and Hg-M4-D in which the CEC is not satisfied by $\mathrm{Na}^{+}$and/or $\mathrm{Hg}^{2+}$ (Fig. 1). The small intensity of $\mathrm{Hg} \mathrm{M}$ line in the EDX spectra of Hg-M4-A and Hg-M4-B (Fig. S2) could be explained by this leached $\mathrm{Al}^{3+}$ to the interlayer space (Fig. S3).

In general, the ${ }^{29} \mathrm{Si}$ MAS NMR spectra can be described as a wide band in the range between -70 ppm and $-95 \mathrm{ppm}$, associated with $\mathrm{Q}^{3}(\mathrm{mAl})$ with $0 \leq \mathrm{m} \leq 3$ environments on phyllosilicates 2:1 (Fig. 4). The differences observed in the spectra (relative intensities and shifts) are due to the different quantity of $\mathrm{Q}^{3}(\mathrm{mAl})$ sites expected in the micas (Alba et al., 2006; Pavón et al., 2014).

In the X-M4 (Fig. 4), ${ }^{29}$ Si peaks shift to lower frequency values when the ionic radius of the cations increases (lower hydrated radius). In the samples with the lowest layer charge, this displacement is also shown, but it is smaller than in the highest charged mica, due to the lower cations concentration in the interlayer space.

The exchanged reaction causes changes in the relative intensity of the signals and a line broadening of the ${ }^{29} \mathrm{Si}$ MAS NMR signals, similar to that observed in the tetrahedral ${ }^{27}$ Al MAS NMR signal (Fig. S3), probably due to the distortion exerted on the tetrahedral $\mathrm{Si}^{4+}$ as consequence of the location of the interlayer cation in the pseudohexagonal cavity 
(Alvero et al., 1994). In Hg-M4-D, the signal of $\Upsilon$-ringwoodite at -81.3 ppm, (Stebbins et al., 2009) observed by XRD, overlaps with the ${ }^{29} \mathrm{Si}$ signals of mica.

A d d001 value of $1.22 \mathrm{~nm}$ implies an estimated interlayer space height of $0.26 \mathrm{~nm}$ and as the Van der Waal diameter of water is $0.28 \mathrm{~nm}$ (Finney, 2001), a steric effect has to be considered to accommodate the fully hydrated cation in the middle of the interlayer space. Therefore, the cations trend to form an inner complex with the basal oxygen plane that provokes a change of the chemical shift and a broadening line of the ${ }^{29} \mathrm{Si}$ and ${ }^{27} \mathrm{Al}$ MAS NMR signals.

\subsection{Effect of the heavy metal initial salt concentration}

Comparing A and B samples, the effect of the initial heavy metal concentration, $C_{0}$, on the efficiency of the cation exchange reaction can be inferred.

When a higher $C_{0}$ is offered (X-M4-B), the amount of desorbed $\mathrm{Na}^{+}$and adsorbed $\mathrm{X}^{2+}$ increases, indicating that the exchange reaction is favoured (Fig. 1), being the only exception the exchange with $\mathrm{Cd}^{2+}$ where nearly the same quantity of metal is adsorbed nevertheless the initial $C_{0}$. In this case, the distribution ratio between liquid and solid, $K_{d}$, remains constant $\left(60.7 \mathrm{~L} / \mathrm{kg}\right.$ for Cd-M4-A and Cd-M4-B) and a saturation of the $\mathrm{Cd}^{2+}$ active site can be concluded.

$\mathrm{XRD}$ data reveals that the crystallinity of the samples is not affected by $C_{0}$, and neither the basal space that does not change after increasing the initial heavy metal concentration. However, the exchange reaction with $\mathrm{Hg}^{2+}$ produces that at higher $C_{0}(\mathrm{Hg}-\mathrm{M} 4-\mathrm{B})$ only one 001 reflection at $1.36 \mathrm{~nm}$ is observed whereas in the EDX spectra none $\mathrm{Hg} \mathrm{M}$ line can be seen. ${ }^{27} \mathrm{Al}$ MAS NMR reveals an increase in the octahedral $\mathrm{Al}^{3+}$ signal which is accompanied by a nearly absence of the exchangeable $\mathrm{Na}^{+}$signal in the ${ }^{23} \mathrm{Na}$ MAS NMR, thus, indicates the leaching of $\mathrm{Al}^{3+}$ and probably $\mathrm{H}_{3} \mathrm{O}^{+}$cations are responsible for the 
observed basal spacing. Non-change is observed in the local order of the aluminosilicate structure, see ${ }^{29}$ Si MAS NMR spectra in Fig. 4, with increasing of the initial heavy metal concentration.

\subsection{Effect of the counterion}

The analysis of the samples of series B and C (Table 1) allows evaluating the effect of the counterion on the efficiency of the cation exchange reaction. Neal and Sposito (Neal and Sposito, 1986) assumed that $\mathrm{Cl}^{-}$and $\mathrm{NO}_{3}^{-}$have weak effect on metal ion adsorption but our results demonstrate that this is not true for high charge swelling micas, where their adsorption ability for heavy metal cations is affected.

$\mathrm{Na}^{+}$leaching is favoured in presence of $\mathrm{Cl}^{-}(\mathrm{X}-\mathrm{M} 4-\mathrm{B})$ as reported by Sharma and Sharma (Sharma and Sharma, 2013) who observed that $\mathrm{Cl}^{-}$anion seems to have promoted alkali cation leaching in comparison with other anionic medium. However, the medium has an unlike behaviour in the heavy metal adsorption: while the adsorption of $\mathrm{Cd}^{2+}$ and $\mathrm{Hg}^{2+}$ is disfavoured in the presence of $\mathrm{Cl}^{-}$, the opposite occurred for the $\mathrm{Pb}^{2+}$ adsorption. The reason may be the formation of $\mathrm{Pb}(\mathrm{OH})_{2}$ species in the presence of $\mathrm{NO}_{3}{ }^{-}$, both the $p H$ and $E_{H}$ conditions in the $\mathrm{NO}_{3}{ }^{-}$medium (Fig. S1) favoured this formation, and the formation of complexes with $\mathrm{Cl}^{-}$in the case of $\mathrm{Cd}^{2+}$ and $\mathrm{Hg}^{2+}$ that diminish the adsorption (El-Hefnawy et al., 2014; Ugochukwu et al., 2013).

A higher hydration of the layer is observed in the case of $\mathrm{Cl}^{-}$as counterion in comparison with $\mathrm{NO}_{3}{ }^{-}$(Fig. 2). Sato (Sato, 2008) has reported that the water activity on porewater of swelling smectites depends on the counterion, thus, the water content is higher when the counterion is $\mathrm{Cl}^{-}$instead of $\mathrm{NO}_{3}{ }^{-}$. No local order change is observed in the MAS NMR spectra. 


\subsection{Effect of the mica/heavy metal solution stirring during equilibration}

In general, no or minor changes are observed as consequence of the equilibration process between Na-M4 and heavy metal solutions (X-M4-C vs X-M4-D). In the case of $\mathrm{Pb}^{2+}$ and $\mathrm{Cd}^{2+}$, the adsorbed heavy metal amount is higher in X-M4-D (Fig. 1) as a consequence of the higher quantity offered to the samples. However, the desorbed $\mathrm{Na}^{+}$ decreases in X-M4-D (Fig. 1), which infers a lower exchange capacity of $\mathrm{Na}^{+}$by $\mathrm{X}^{2+}$, the exchange reaction being more efficient in X-M4-C. No structural changes are observed as a consequence of the equilibration process.

For $\mathrm{Hg}^{2+}$, the opposite trend is observed, desorbed $\mathrm{Na}^{+}$is higher in $\mathrm{Hg}-\mathrm{M} 4-\mathrm{D}$ and adsorbed $\mathrm{Hg}^{2+}$ is higher in $\mathrm{Hg}-\mathrm{M} 4-\mathrm{C}$. The high acid reaction medium that provokes a quite high leached $\mathrm{Al}^{3+}$ and partially exchanges the interlayer $\mathrm{Na}^{+}$may be the responsible of that behaviour (Fig. S3). No other structural changes are observed as a consequence of the equilibration process.

\subsection{Effect of the layer charge}

Finally, we focus on structural parameters of the exchangeable material and the influence of the mica layer charge on their ability to exchange their interlayer sodium cations by heavy metals ones is analysed.

The amount of desorbed $\mathrm{Na}^{+}$and absorbed $\mathrm{X}^{2+}$ increases when layer charge decreases, indicating that the strong electrostatic attraction between the charged surface of Na-M4 difficults the diffusion of $\mathrm{X}^{2+}$ into the interlayer space (Pavón et al., 2014; Pavon et al., 2013). In general, those synthetic micas has higher heavy metal exchange capacity than natural and modified smectites, bentonite, kaolinite or zeolite (Rajec et al., 1999; Uddin, 2017). The only exception was the adsorption of $\mathrm{Hg}^{2+}$ on hydroxyapatite that was higher 
(Uddin, 2017) (2541.8 meq/kg vs 515 or 1878.5 meq/kg on Hg-M4-D and Hg-M2-D, respectively).

Despite of the different cation exchange capacity of Na-M2 and Na-M4 (2475.25 $\mathrm{meq} / \mathrm{kg}$ and $4694.84 \mathrm{meq} / \mathrm{kg}$, respectively), the swelling of the layer remains constant (similar $d_{001}$ value, Fig. 2), except for $\mathrm{Cd}^{2+}$. When the layer charge decreases, Na-M2, the position of the 001 reflection of the Cd-M2-D shifts to a lower $2 \theta$ value, which corresponds to higher basal space (up to $1.45 \mathrm{~nm}$ ). This increased layer separation for the Mica-2 is likely to be due to small cations located in a two layer closer to the surface and can adsorb more water molecules (Pavon et al., 2013).

In addition, silicate layer charge also affects the formation of inner sphere complexes. When layer charge increases, the negative charge of the surface also increases, and, therefore, the materials turn out to have more tendency on forming inner sphere complex and the effect of the interlayer cation is more evident, as can be seen in the displacement of the chemical shift and line broadening of the ${ }^{29} \mathrm{Si}$ and ${ }^{27} \mathrm{Al}$ MAS NMR signals (Fig. 4 and Fig. S3).

\section{Conclusions}

In this contribution, the selectivity for the sodium exchange by heavy metals cations is explored for a series of high charge swelling micas, analysing different experimental conditions. The efficiency of cation exchange and the adsorption mechanism depend on the experimental conditions, but, in general, the maximum adsorption has the trend: $\mathrm{Hg}^{2+}$ $>\mathrm{Pb}^{2+}>\mathrm{Cd}^{2+}$ and is quite higher than in natural and modified clay minerals and the exchange reaction is more efficient when layer charge diminishes. The metal cations are located in the pseudohexagonal cavity as an inner sphere complex which is favoured as the layer charge increases and depends on the physical properties of the heavy metal. 
However, the interlayer structure of the hydrated mica is retained during the ion-exchange reaction.

\section{Supporting information}

The Supporting Information is available free of charge on the Publications website.

Experimental variables and $p H$ of initial and post-exchange reaction solutions. Pourbaix diagram of aqueous solution of metals in the initial solution. EDX spectra of lamellar particles for all the cation exchange conditions. ${ }^{27} \mathrm{Al}$ MAS NMR spectra of Na-M4 and Na-M2 after metal adsorption at different experimental conditions.

\section{Acknowledgements}

The authors would like to thank the Junta de Andalucía (Spain) and FEDER (Proyecto de Excelencia de la Junta de Andalucía, project P12-FQM-567), to the Spanish State Program $\mathrm{R}+\mathrm{D}+\mathrm{I}$ oriented societal challenges and FEDER (Project MAT201563929-R) for financial support. F.J. Osuna thanks his grant to the training researcher program associated to the excellence project of Junta de Andalucía (P12-FQM-567). 
Table S1

Cation exchange conditions $\left(\mathrm{X}=\mathrm{Pb}^{2+}, \mathrm{Cd}^{2+}, \mathrm{Hg}^{2+}\right)$

\begin{tabular}{llllll}
\hline & counterion & $\begin{array}{l}C_{0} \\
(\mathrm{meq} / \mathrm{l})\end{array}$ & $\begin{array}{l}L / S \\
(\mathrm{ml} / \mathrm{g})\end{array}$ & $\begin{array}{l}\text { Total } C_{0} \\
(\mathrm{meq} / \mathrm{kg})\end{array}$ & stirring \\
\hline $\mathrm{X}-\mathrm{M} 4-\mathrm{A}$ & $\mathrm{Cl}^{-}$ & 35.3 & 50 & 7042.3 & magnetic \\
$\mathrm{X}-\mathrm{M} 4-\mathrm{B}$ & $\mathrm{Cl}^{-}$ & 47 & 50 & 9389.7 & magnetic \\
$\mathrm{X}-\mathrm{M} 4-\mathrm{C}$ & $\mathrm{NO}_{3}{ }^{-}$ & 47 & 50 & 9389.7 & magnetic \\
$\mathrm{X}-\mathrm{M} 4-\mathrm{D}$ & $\mathrm{NO}_{3}{ }^{-}$ & 47 & 200 & 38779.4 & end-over \\
X-M2-D & $\mathrm{NO}_{3}{ }^{-}$ & 24.8 & 200 & 19802.0 & end-over \\
\hline
\end{tabular}

$C E C(\mathrm{Na}-\mathrm{M} 2)=2475.25 \mathrm{meq} / \mathrm{kg}$ and $C E C(\mathrm{Na}-\mathrm{M} 4)=4694.84 \mathrm{meq} / \mathrm{kg}$

\section{Table 2}

Physicochemical properties of heavy metals ${ }^{\mathrm{a}}$

\begin{tabular}{llll}
\hline & $\mathrm{Pb}^{2+}$ & $\mathrm{Cd}^{2+}$ & $\mathrm{Hg}^{2+}$ \\
\hline$r(\AA)$ & 1.19 & 0.95 & 1.02 \\
$\eta$ & 8.46 & 10.29 & 7.70 \\
$p K_{H}$ & 7.70 & 10.01 & 3.40 \\
\hline${ }^{a} r$ represents the effective ionic radius, \\
$\eta$ represents the hardness and $p K_{H}$ is \\
the hydrolysis constant.
\end{tabular}




\section{FIGURE CAPTION}

Fig. 1. $\mathrm{X}^{2+}$ sorption parameters on $\mathrm{X}-\mathrm{M} n(n=2$ and 4$)$. The dash lines mark the $C E C$ of the Na-Mn.

Fig. 2. $\mathrm{XRD}$ of $\mathrm{X}-\mathrm{M} n$ at different experimental conditions $\left(\mathrm{X}=\mathrm{Pb}^{2+}, \mathrm{Cd}^{2+}\right.$ or $\mathrm{Hg}^{2+}$ and $n=2$ or 4$) . *=\mathrm{PbCl}(\mathrm{OH}) \mathrm{PDF} 04-011-5179 ; \mathrm{o}=\mathrm{PbO} \cdot 4 \mathrm{H}_{2} \mathrm{O}$ PDF 00-018-0701 or $\mathrm{HgO} \mathrm{PDF}$ 04-007-4740; $\mathrm{f}=\mathrm{PbF}_{2}$ PDF 04-005-4701; $\mathrm{h}=\mathrm{Hg}\left(\mathrm{NO}_{3}\right)_{2} \cdot 3 \mathrm{H}_{2} \mathrm{O}$ PDF 00-031-0855; e=spinel $\left(\mathrm{MgAl}_{2} \mathrm{O}_{4}\right)$ PDF 04-006-9814; +=MgO PDF 01-080-4193; $\wedge=$ Ringwoodite $\Upsilon-\mathrm{Mg}_{2} \mathrm{SiO}_{4}$ PDF 01-077-8396

Fig. 3. ${ }^{23} \mathrm{Na}$ MAS NMR spectra of $\mathrm{X}-\mathrm{M} n$ at different experimental conditions $\left(\mathrm{X}=\mathrm{Pb}^{2+}\right.$, $\mathrm{Cd}^{2+}$ or $\mathrm{Hg}^{2+}$ and $n=4$ or 2 ).

Fig. 4. ${ }^{29} \mathrm{Si}$ MAS NMR spectra of $\mathrm{X}-\mathrm{M} n$ at different experimental conditions $\left(\mathrm{X}=\mathrm{Pb}^{2+}\right.$, $\mathrm{Cd}^{2+}$ or $\mathrm{Hg}^{2+}$ and $n=4$ or 2$)$. 
Fig. 1
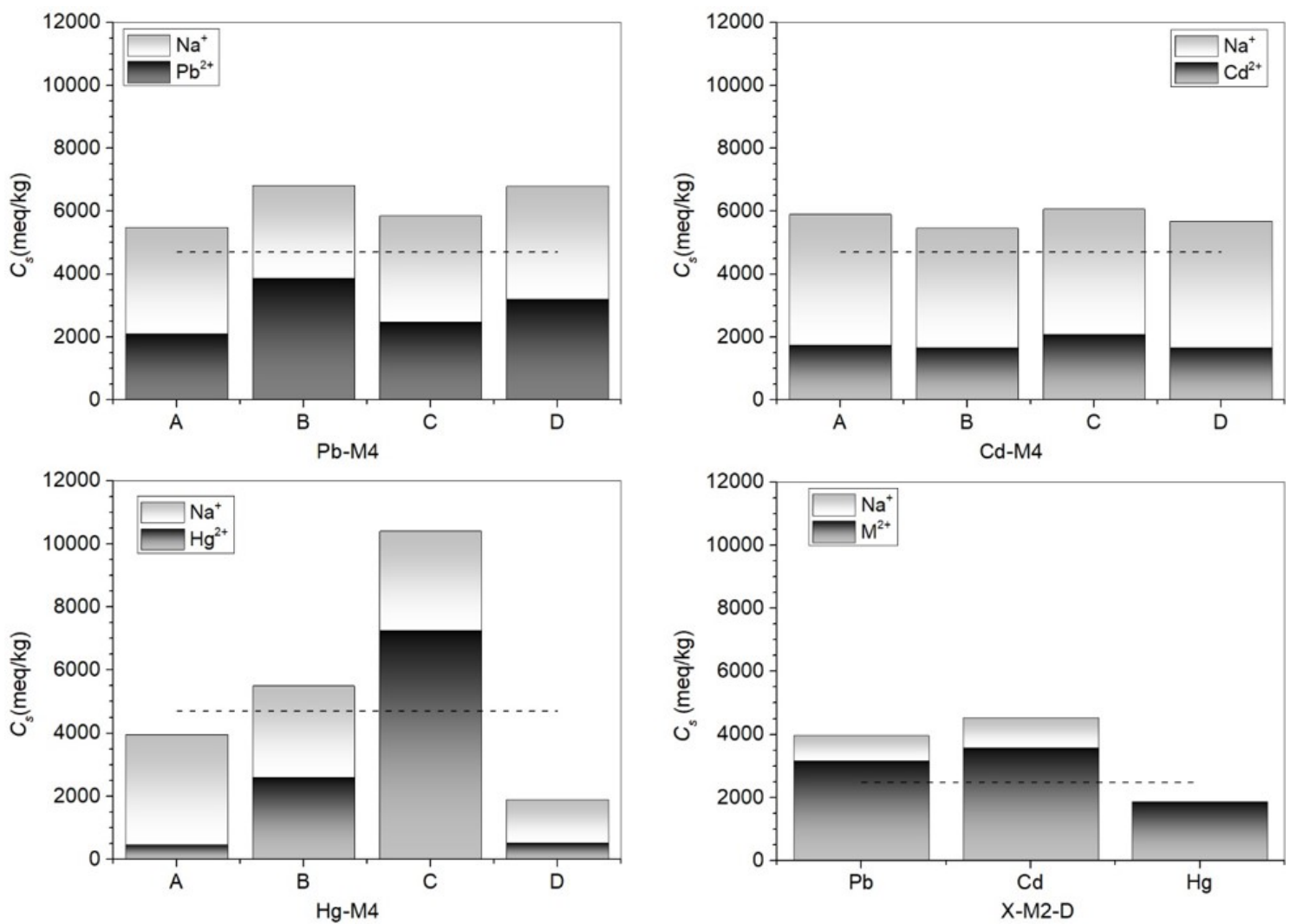
Fig. 2
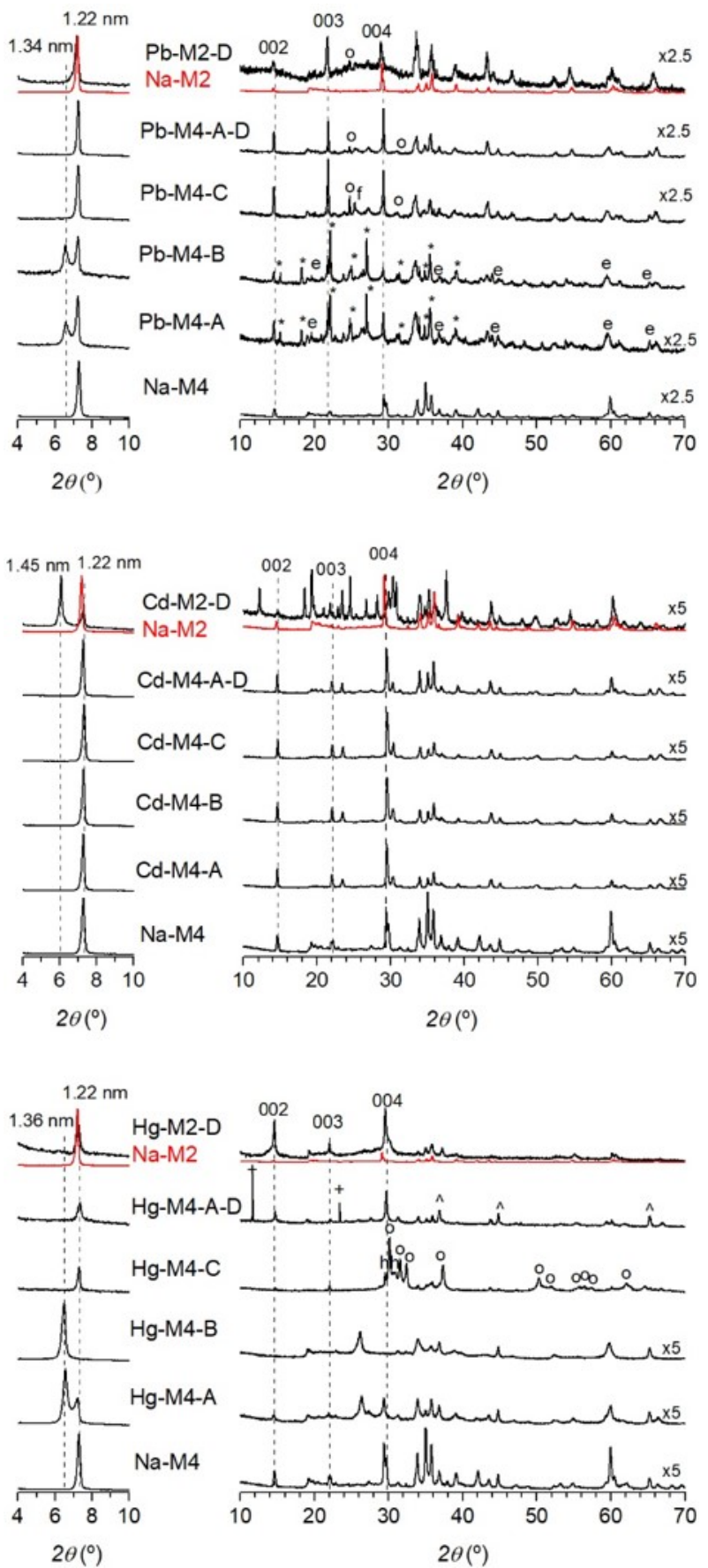
Fig. 3
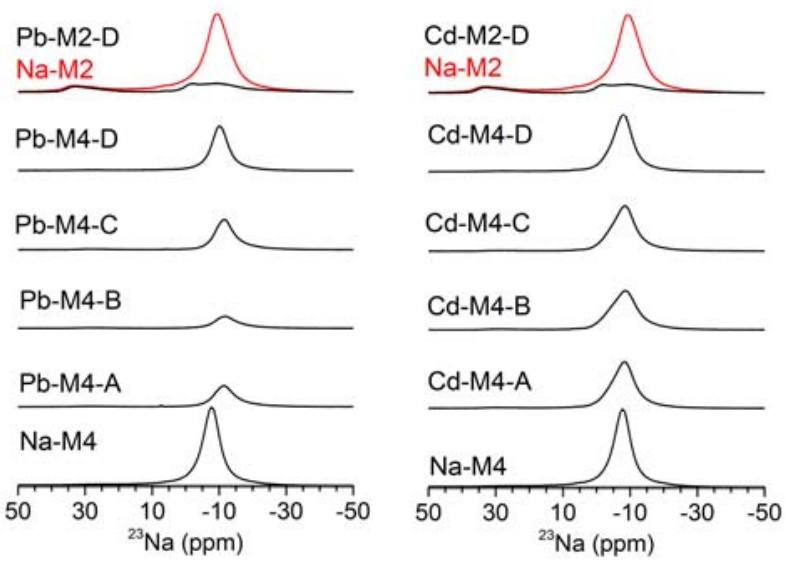

$\mathrm{Hg}-\mathrm{M} 2-\mathrm{D}$
$\mathrm{Na}-\mathrm{M} 2$

Hg-M4-D

Hg-M4-C

Hg-M4-B

Hg-M4-A

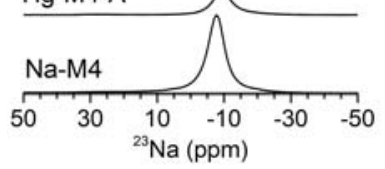


Fig. 4

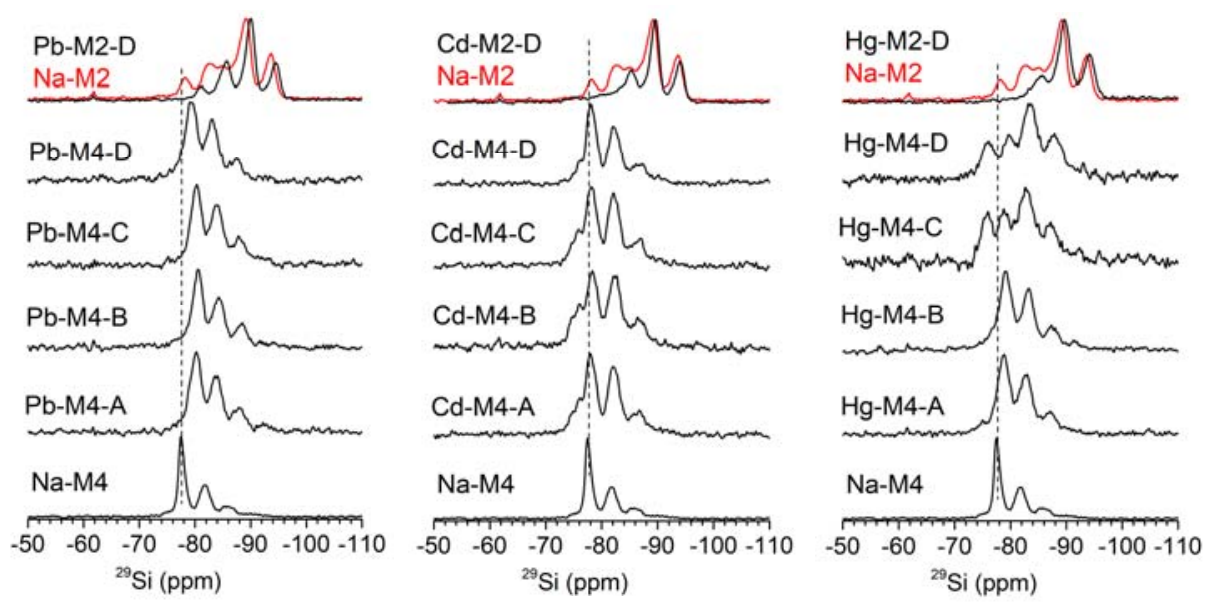


GRAPHICAL ABSTRACT

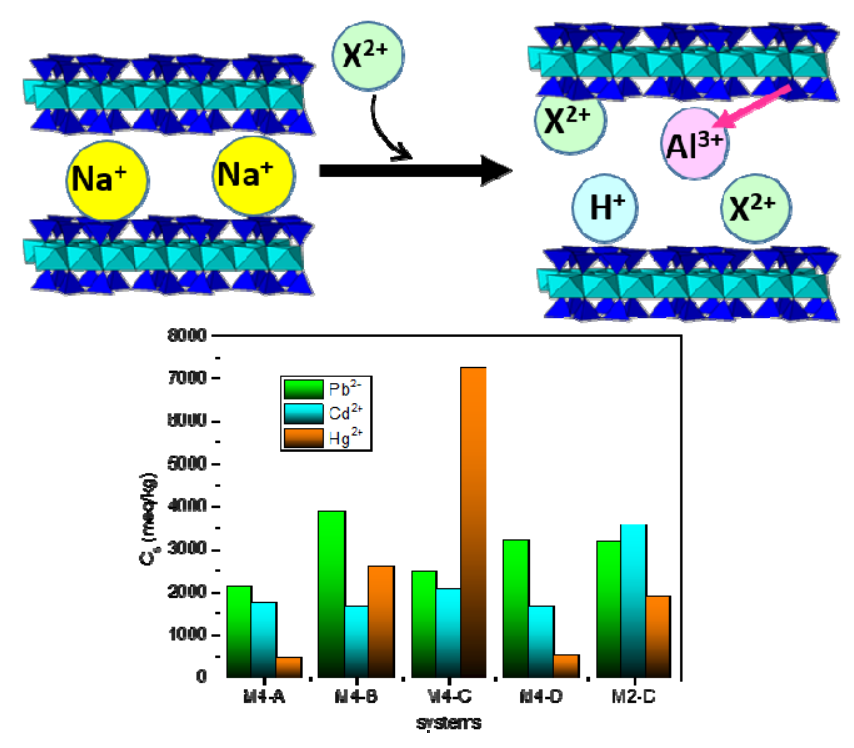




\section{References}

Al-Saleh, I., Coskun, S., Mashhour, A., Shinwari, N., El-Doush, I., Billedo, G., Jaroudi, K., Al-Shahrani, A., Al-Kabra, M., Mohamed, G.E.D., 2008. Exposure to heavy metals (lead, cadmium and mercury) and its effect on the outcome of in-vitro fertilization treatment. Int. J. Hyg. Environ. Health 211, 560-579.

Alba, M.D., Becerro, A.I., Castro, M.A., Perdigon, A.C., 2001a. Hydrothermal reactivity of Lu-saturated smectites: Part I. A long-range order study. Am. Miner. 86, 115-123.

Alba, M.D., Becerro, A.I., Castro, M.A., Perdigon, A.C., 2001b. Hydrothermal reactivity of Lu-saturated smectites: Part II. A short-range order study. Am. Miner. 86, 124-131.

Alba, M.D., Castro, M.A., Naranjo, M., Pavon, E., 2006. Hydrothermal reactivity of Na-n-micas $(\mathrm{n}=2,3,4)$. Chem. Mat. 18, 2867-2872.

Alvero, R., Alba, M.D., Castro, M.A., Trillo, J.M., 1994. Reversible migration of lithium in montmorillonites. J. Phys. Chem. 98, 7848-7853.

Churchman, G.J., Gates, W.P., Theng, B.K.G., Yuan, G., 2006. Chapter 11.1 Clays and Clay Minerals for Pollution Control, in: Bergaya, F., Theng, B.K.G., Lagaly, G. (Eds.), Developments in Clay Science. Elsevier, pp. 625-675.

El-Hefnawy, M.E., Selim, E.M., Assaad, F.F., Ismail, A.I., 2014. The Effect of Chloride and Sulfate Ions on the Adsorption of $\mathrm{Cd}^{2+}$ on Clay and Sandy Loam Egyptian Soils. Sci. World J., 6.

Finney, J.L., 2001. The water molecule and its interactions: the interaction between theory, modelling, and experiment. J. Mol. Liq. 90, 303-312.

Fu, F.L., Wang, Q., 2011. Removal of heavy metal ions from wastewaters: A review. J. Environ. Manage. 92, 407-418. 
Garcia-Jimenez, M.J., Cota, A., Osuna, F.J., Pavon, E., Alba, M.D., 2016. Influence of temperature and time on the $\mathrm{Eu}^{3+}$ reaction with synthetic Na-Mica-n ( $\mathrm{n}=2$ and 4$)$. Chem. Eng. J. 284, 1174-1183.

Gonzalez-Davila, M., Santana-Casiano, J.M., Millero, F.J., 2007. Use of pitzer equations to examine the formation of Mercury(II) hydroxide and chloride complexes in $\mathrm{NaClO}_{4}$ media. Aquat. Geochem. 13, 339-355.

Jimenez-Castaneda, M.E., Medina, D.I., 2017. Use of Surfactant-Modified Zeolites and Clays for the Removal of Heavy Metals from Water. Water 9.

Kang, S.Y., Lee, J.U., Moon, S.H., Kim, K.W., 2004. Competitive adsorption characteristics of $\mathrm{Co}^{2+}, \mathrm{Ni}^{2+}$, and $\mathrm{Cr}^{3+}$ by IRN-77 cation exchange resin in synthesized wastewater. Chemosphere 56, 141-147.

Kim, H.N., Ren, W.X., Kim, J.S., Yoon, J., 2012. Fluorescent and colorimetric sensors for detection of lead, cadmium, and mercury ions. Chem. Soc. Rev. 41, 3210-3244. Kodama, T., Komarneni, S., 1999. Na-4-mica: $\mathrm{Cd}^{2+}, \mathrm{Ni}^{2+}, \mathrm{Co}^{2+}, \mathrm{Mn}^{2+}$ and $\mathrm{Zn}^{2+}$ ion exchange. J. Mater. Chem. 9, 533-539.

Kodama, T., Komarneni, S., Hoffbauer, W., Schneider, H., 2000. Na-4-mica: simplified synthesis from kaolinite, characterization and $\mathrm{Zn}, \mathrm{Cd}, \mathrm{Pb}, \mathrm{Cu}$ and $\mathrm{Ba}$ uptake kinetics. J. Mater. Chem. 10, 1649-1653.

Kodama, T., Ueda, M., Nakamuro, Y., Shimizu, K., Komarneni, S., 2004. Ultrafine na4-mica: Uptake of alkali and alkaline earth metal cations by ion exchange. Langmuir 20, $4920-4925$.

Matusik, J., Wscislo, A., 2014. Enhanced heavy metal adsorption on functionalized nanotubular halloysite interlayer grafted with aminoalcohols. Appl. Clay Sci. 100, 5059. 
Naranjo, M., Castro, M.A., Cota, A., Osuna, F.J., Pavon, E., Alba, M.D., 2015.

Synthesis temperature effect on Na-Mica-4 crystallinity and heteroatom distribution. Micropor. Mesopor. Mat. 204, 282-288.

Neal, R.H., Sposito, G., 1986. Effects of soluble organic-matter and sewage-sludge amendments on cadmium sorption by soils at low cadmium concentrations. Soil Science $142,164-172$.

O'Connell, D.W., Birkinshaw, C., O'Dwyer, T.F., 2008. Heavy metal adsorbents prepared from the modification of cellulose: A review. Bioresour. Technol. 99, 67096724

Park, M., Kim, H.J., Kim, K.S., Duckworth, O.W., Komarneni, S., 2012. HydroniumPromoted Equilibrium Mechanism for the Alkali Metal Cation Exchange Reaction in Na-4-Mica. J. Phys. Chem. C 116, 18678-18683.

Pavón, E., Castro, M.A., Cota, A., Osuna, F.J., Pazos, M.C., Alba, M.D., 2014. Interaction of Hydrated Cations with Mica-n $(n=2,3$ and 4) Surface. J. Phys. Chem. C $118,2115-2121$.

Pavon, E., Castro, M.A., Naranjo, M., Orta, M.M., Pazos, M.C., Alba, M.D., 2013. Hydration properties of synthetic high-charge micas saturated with different cations: An experimental approach. Am. Miner. 98, 394-400.

Pavon, E., Osuna, F.J., Alba, M.D., Delevoye, L., 2014. Direct evidence of Lowenstein's rule violation in swelling high-charge micas. Chem. Commun. 50, 69846986.

Pazos, M.C., Castro, M.A., Cota, A., Osuna, F.J., Pavon, E., Alba, M.D., 2017. New insights into surface-functionalized swelling high charged micas: Their adsorption performance for non-ionic organic pollutants. J. Ind. Eng. Chem. 52, 179-186. 
Pearson, R.G., 1988. Absolute electronegativity and hardness - application to inorganicchemistry. Inorg. Chem. 27, 734-740.

Persson, I., 2010. Hydrated metal ions in aqueous solution: How regular are their structures? Pure Appl. Chem. 82, 1901-1917.

Rajec, P., Macasek, F., Misaelides, P., 1999. Sorption of heavy metals and radionuclides on zeolites and clays, in: Misaelides, P., Macasek, F., Pinnavaia, T.J., Colella, C. (Eds.), Natural Microporous Materials in Environmental Technology, pp. 353-363.

Sanz, J., Serratosa, J.M., 1984. Si-29 and Al-27 high-resolution MAS-NMR spectra of phyllosilicates. J. Am. Chem. Soc. 106, 4790-4793.

Sato, H., 2008. Thermodynamic model on swelling of bentonite buffer and backfill materials. Phys. Chem. Earth 33, S538-S543.

Sharma, V., Sharma, K.N., 2013. Influence of Accompanying Anions on Potassium Retention and Leaching in Potato Growing Alluvial Soils. Pedosphere 23, 464-471. Srinivasan, R., 2011. Advances in Application of Natural Clay and Its Composites in Removal of Biological, Organic, and Inorganic Contaminants from Drinking Water. Advances in Materials Science and Engineering.

Stebbins, J.F., Panero, W.R., Smyth, J.R., Frost, D.J., 2009. Forsterite, wadsleyite, and ringwoodite $\left(\mathrm{Mg}_{2} \mathrm{SiO}_{4}\right)$ : $\mathrm{Si}-29 \mathrm{NMR}$ constraints on structural disorder and effects of paramagnetic impurity ions. Am. Miner. 94, 626-629.

Syrmanova, K., Suleimenova, M.T., Sarypbekova, N.K., Botabaev, N.E., Kaldybekova, J.B., 2016. Research of Porization and Adsorptions in High-Porous Adsorptive Layers of Vermiculite. Orient. J. Chem. 32, 1319-1328. 
Takahashi, Y., Tada, A., Shimizu, H., 2004. Distribution pattern of rare earth ions between water and montmorillonite and its relation to the sorbed species of the ions. Anal. Sci. 20, 1301-1306.

Uddin, M.K., 2017. A review on the adsorption of heavy metals by clay minerals, with special focus on the past decade. Chem. Eng. J. 308, 438-462.

Ugochukwu, N., Mohamed, I., Ali, M., Iqbal, J., Fu, Q.L., Zhu, J., Jiang, G.J., Hu, H.Q., 2013. Impacts of inorganic ions and temperature on lead adsorption onto variable charge soils. Catena 109, 103-109.

Yuan, G., 2004. Natural and Modified Nanomaterials as Sorbents of Environmental Contaminants. J. Environ. Sci. Health., Part A 39, 2661-2670.

Yuan, G.D., Theng, B.K.G., Churchman, G.J., Gates, W.P., 2013. Chapter 5.1 - Clays and Clay Minerals for Pollution Control, in: Bergaya, F., Lagaly, G. (Eds.), Developments in Clay Science. Elsevier, pp. 587-644.

Zhu, R., Zhou, Q., Zhu, J., Xi, Y., He, H., 2015. Organo-clays as sorbents of hydrophobic organic contaminants: Sorptive characteristics and approaches to enhancing sorption capacity. Clay Clay Min. 63, 199-221. 